Cukurova Üniversitesi Mühendislik Fakültesi Dergisi, 36(4), ss. 1005-1018, Aralık 2021

Cukurova University Journal of the Faculty of Engineering, 36(4), pp. 1005-1018, December 2021

\title{
Harbiye (Hatay) Şelaleler Bölgesindeki Şev Duraysızlıklarının Mühendislik Jeolojisi Açısından Değerlendirilmesi
}

\author{
Mehmet DUYAN ${ }^{1}$ ORCID $0000-0001-6795-2338$ \\ Sedat TÜRKMEN ${ }^{* 1}$ ORCID 0000-0002-9567-5545
}

${ }^{1}$ Çukurova Üniversitesi, Jeoloji Mühendisliği Bölümü, Adana

Geliş tarihi: 27.04.2021 Kabul tarihi: 10.12.2021

Attf şekli/ How to cite: DUYAN, M., TÜRKMEN, S., (2021). Harbiye (Hatay) Şelaleler Bölgesindeki Şev Duraysızlıklarının Mühendislik Jeolojisi Açısından Değerlendirilmesi. Çukurova Üniversitesi, Mühendislik Fakültesi Dergisi, 36(4), 1005-1018.

$\ddot{\mathbf{O} z}$

Bu çalışmada, Hatay İli, Defne İlçesi Harbiye Mahallesi Șelaleler bölgesinde bulunan şevlerin duraylılığı değerlendirilmiş ve bölgenin heyelan riskinin azaltılması ile ilgili uygun çözümlerin ortaya konulması amaçlanmıştır. Çalışma kapsamında inceleme alanında sondajlar, presiyometre deneyleri ve inklinometre ölçümleri yapılmışıır. İnceleme alanında şev duraylılık problemlerinin bulunduğu bölgedeki litolojik birimler siltli kil ve kiltaşıdır. Her birime ait kayma direnci parametreleri belirlenmiş ve Slide 3D yazılımı ile üç boyutlu şev stabilite analizi yapılmıştır. Şev stabilite analizlerinde, direk kesme deneyi, geri analiz ve RocData ile olmak üzere üç farklı yöntem kullanılarak elde edilen kayma dayanım parametreleri ayrı ayrı göz önünde bulundurulmuş ve bu üç farklı durum için güvenlik katsayısı hesaplamaları yapılmıștır. Güvenlik katsayısı hem statik durum hem de deprem durumu senaryoları için hesaplanmıştır. İlk senaryoda, direk kesme deneyinden elde edilen kiltaşına ait parametreler kullanılmıştır. İkinci senaryoda, RocData yazılımı ile elde edilen kiltaşına ait parametreler kullanılmıştır. Üçüncü senaryoda ise geri analiz ile elde edilen kiltaşına ait parametreler kullanılmıştır. Tüm senaryolar değerlendirilmiş ve geri analiz ile elde edilen kiltaşına ait kayma parametrelerinin bulunduğu üçüncü senaryonun gerçeğe en yakın koşulları yansittığı görülmüştür.

Anahtar Kelimeler: Hatay, Heyelan, Geri analiz, Şev stabilitesi, RocData

\section{Assessment of Slope Instability on Waterfalls Region in terms of Engineering Geology (Harbiye, Hatay)}

\begin{abstract}
In this study, the stability of slopes located on Harbiye Waterfalls Region of Defne District (Hatay Province) was evaluated and suitable solutions are aimed to reveal. Within the scope of study drillings, pressure meter tests and inclinometer measurements were performed. With laboratory studies, the physical and mechanical properties of soil and rock units were determined. Lithological units, in the study area where slope stability problems exist, belong to lithological units are silty clay and claystone. There is
\end{abstract}

"Sorumlu yazar (Corresponding author): Sedat TÜRKMEN, sturkmen@cu.edu.tr 
filling material on these units. Shear strength parameters of each unit were determined, and threedimensional slope analysis was performed with Slide 3D software. The analyses were carried out in three different scenarios. Both the static state and the earthquake state were calculated for each scenario. In the first scenario, the claystone parameters obtained from the direct shear test were used. In the second scenario, the claystone parameters obtained from RocData software were used. In the third scenario, the claystone parameters obtained from the back analysis were used. All scenarios were evaluated, and it was determined, in the third scenario, the claystone parameters that are obtained from the back analysis reflect the actual conditions.

Keywords: Hatay, Land slide, Back analysis, Slope stability, RocData

\section{GİRIŞ}

Hatay İli Defne İlçesi Harbiye Mahallesi sınırları içerisinde bulunan, yaklaşık 3000 yıllık bir geçmişi olan, binlerce yıllık ağaçların bulunduğu Şelaleler bölgesi doğal güzellikleri Hatay'ın önde gelen turizm bölgelerinden biridir (Şekil 1). Şelale Deresinin aktığı vadinin yamaçları üzerinde konutlar, restoranlar, oteller ve çeşitli el sanat atölyeleri bulunmaktadır. Vadinin dik bir vadi olması, suyun varlığı ve yamaçlar üzerindeki yap1 yükleriyle beraber heyelan potansiyelinin artması sonucunda bu bölgenin doğal tarihi yapısının bozulma riski doğmuş ve yer yer heyelanlar gelişmiş, buna karşı birtakım önlemler alınmaya çalışılmış, ancak heyelan hareketi durdurulamamış ve yerleşim alanlarını tehdit etmeye başlamıştır.

$\mathrm{Bu}$ çalışmada; şelalelerin bulunduğu bölgenin genel jeolojik durumunun incelenmesi, duraysızlığa neden olan faktörlerin ve kayma mekanizmasının tespit edilmesi, geçmiş kaymalara benzer hareketlerin olup olmayacağının irdelenmesi, heyelanlara duyarlı alanların belirlenmesi, bölgenin mühendislik jeolojisinin yorumlanması ve şev stabilitesi ile ilgili alternatif önerilerin sunulması amaçlanmıştır [1].
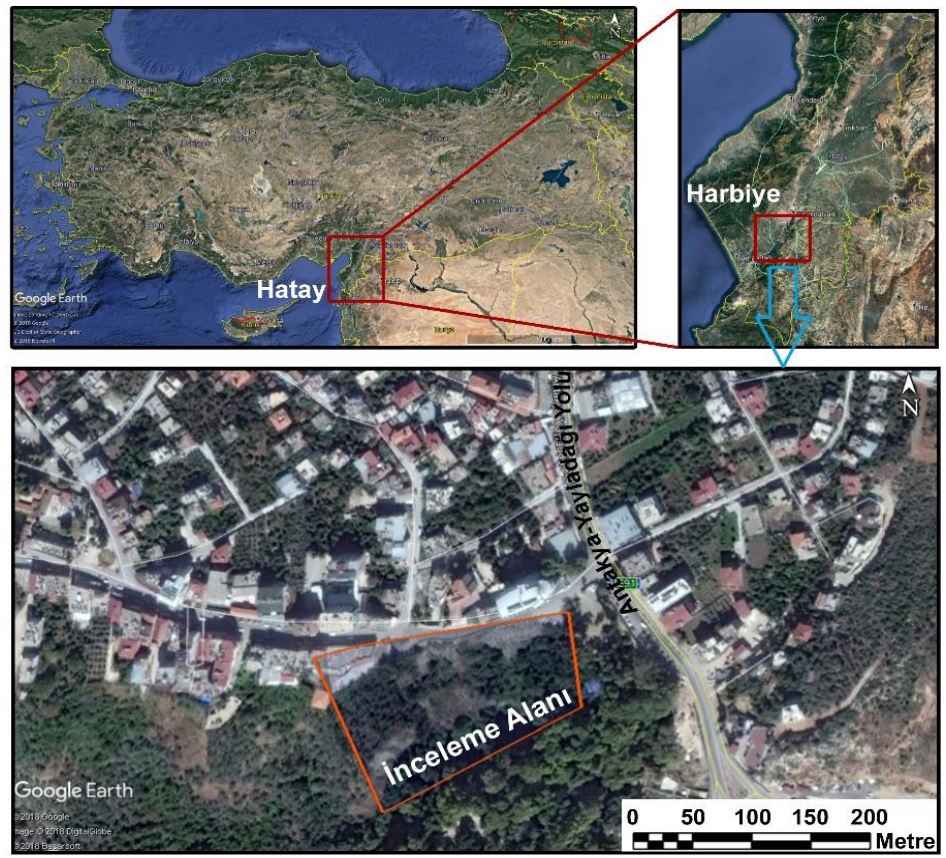

Şekil 1. İnceleme alanı yer bulduru haritası (Google Earth’ten alınmıştır) 


\section{MATERYAL VE METOT}

\subsection{Materyal}

\subsubsection{Harbiye Heyelanı}

Çalışmanın konusunu oluşturan heyelan kiltaşı ağırlıklı litolojilerden oluşan Tepehan Formasyonu içerisinde gerçekleşmiş olup kayan kütle dolgu, siltli kil ve kiltaşı birimlerinden oluşmaktadır. Arazi gözlemleri sonucunda, gerçekleşen kütle hareketinin tamamen dairesel bir kayma olmadığ gözlenmiş bu sebeple hesaplamalarda kayma şekli dairesel olmayan kayma hareketi olarak tanımlanmıştır (Şekil 2).

Şev kaymalarını önlemek amacıyla daha önce inşa edilen istinat duvarı yapılarının yeterli desteği sağlayamadığı görülmüştür. Yapılan gözlemlerde istinat duvarlarının inşa edildiği yerlerde bazı kayma hareketlerinin olduğu gözlemlenmiştir. Kütle hareketinin genişlemesi yörede bulunan yapıları tehdit etmekte olup, bu nedenle bazı yapılar boşaltılmıştır (Şekil 3).

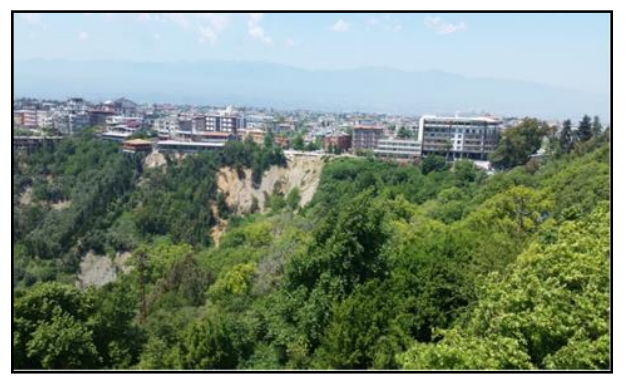

Şekil 2. Heyelan fotoğrafı (karşıdan görünüş)

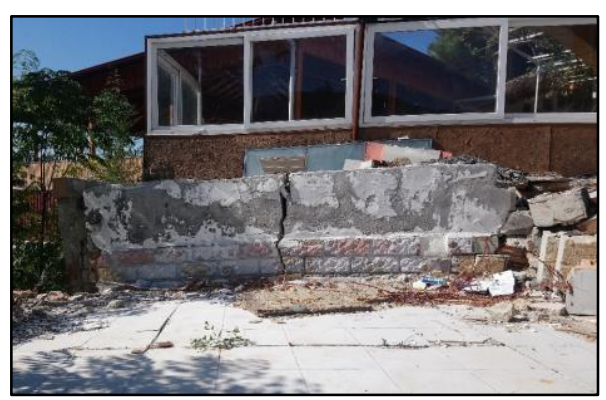

Şekil 3. Bölgedeki kütle hareketinden kaynaklı, bina duvarındaki gözlemlenen deformasyon

\subsection{2. Çalışma Alanı Jeolojisi}

Çalışma alanında yürütülen çalışmalarda gözlemlenen litolojik birimler siltli kil, kiltaşı, kireçtaşı ve travertenlerden oluşmaktadır. Çalışma alanı ve çevresinin jeolojisini Kaleboğazı Formasyonu, Okçular Formasyonu, Tepehan Formasyonu ve güncel traverten ile Alüvyon oluşturmaktadır [2] (Şekil 4).

Siltli kil birimi; kahverengi renkli, katı-çok katı kıvamlı, yer yer kumlu, yüksek plastisitelidir. Kayma hareketlerinin gerçekleştiği şevlerde ve sondajların yapıldığı bölgelerde gözlemlenen bu litolojik birim Tepehan Formasyonuna aittir. İnceleme alanında bazı derinliklerde bu birimin içinde marn seviyeleri gözlemlenmiş fakat litolojiye bakıldığında çoğunlukla yüzeye yakın kısımlarda ayrışmaya bağlı olarak siltli kil biriminin, derinlerde ise kiltaşı-marn yer yer kumtaşının hakim olduğu belirlenmiştir.

Kiltaşı birimi; grimsi mavi renkli, ayrışmamış-az ayrışmış, bozunmamış-az bozunmuş, kırıklı-çok çatlaklı, çok zayıf dayanımlıdır. Kayma hareketlerini gerçekleştiği şevlerde ve sondajların yapıldığı bölgelerde gözlemlenen bu litolojik birim Tepehan Formasyonuna aittir. Arazi gözlemlerinde bu birime ait tabakalar gözlemlenememiş bu sebeple eğim doğrultu ölçümü yapılamamıştır. Ancak sondaj derinliklerinin korelasyonu sonucunda bu birimin birkaç derece eğimli çoğunlukla yataya yakın tabakalı olduğu görülmektedir.

Çalışma alanı çevresinde izlenen diğer birim, kireçtaş1; grimsi-beyaz renkli, orta derecede ayrışmış-çok ayrışmış, az bozunmuş, kırıklı-çok çatlaklı, yüksek dayanımlıdır. Bölgede hem Kaleboğazı hem de Okçular Formasyonuna ait kireçtaşları bulunmaktadır [2].

Traverten birimi ise; Harbiye dolaylarında yaklaşık $5 \mathrm{~km}^{2}$ 'lik bir alanda yayılım gösterir. Genellikle açık kahverengimsi krem renkte, çok boşluklu, bol bitki kalıntısı içerir. Kuvaterner seri içerisinde yer almaktadir. 


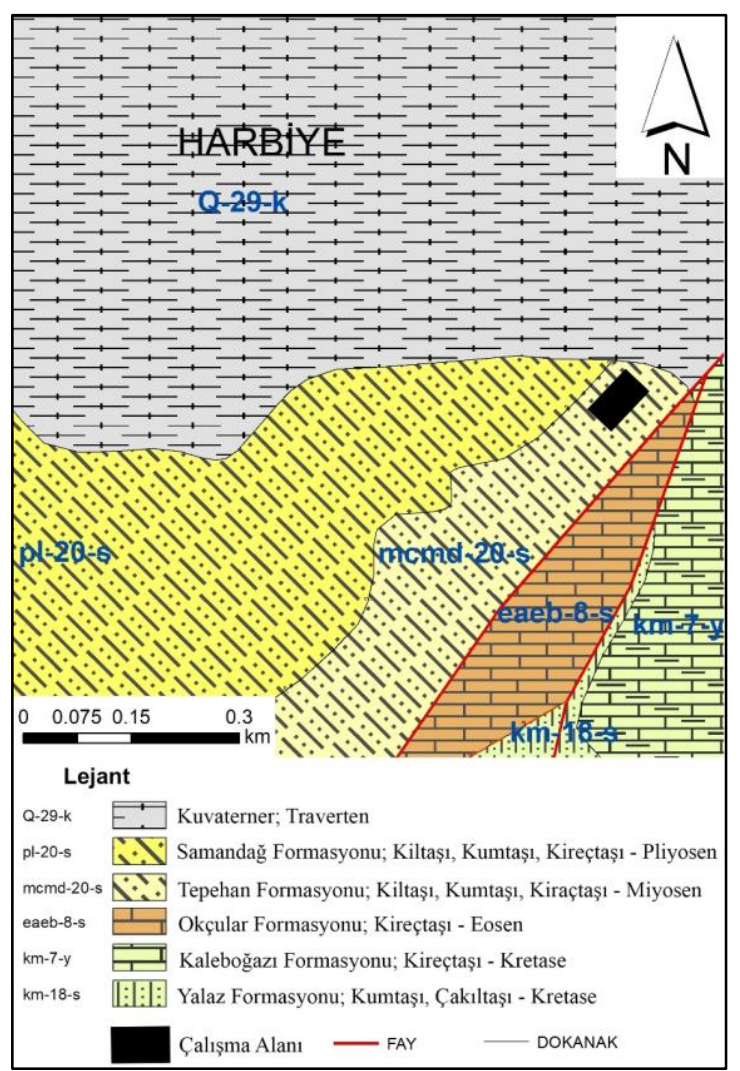

Şekil 4. Çalışma alanı ve çevresinin jeoloji haritası ([2]'den yararlanılmıştır)

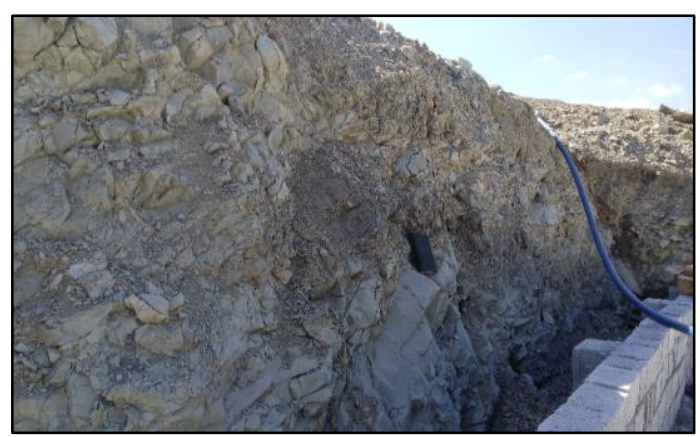

Şekil 5. Tepehan Formasyonunun yakından görünümü

\subsection{Metot}

Yürütülen bu çalışma; literatür çalışmaları, arazi çalışmaları, laboratuvar çalışmaları ve büro çalışmaları olmak üzere dört aşamada gerçekleş̧irilmiştir. $\mathrm{Bu}$ çalışma kapsamında; Akademi Jeolojik Jeoteknik Etüt Proje Mühendislik Müşavirlik İnşaat Sanayi Ticaret Limited Şirketi ve Gür Mühendislik Jeoteknik Sondaj Harita İnşaat Makine Taahhüt Sanayi Ticaret Limited Şirketi tarafindan jeoteknik amaçla yapılan sondajlardan ve inklinometre okumalarından yararlanılmıştır [3].

\subsubsection{Literatür Çalıșmaları}

Arazi çalışması öncesinde çalışma alanı ve yakın çevresiyle ilgili literatür araştırması yapılmış olup çalışma alanı ve yakın çevresiyle ilgili yapılan tezler ve makaleler incelenmiş, bölgede yapılmış arazi ve laboratuvar çalışmaları elde edilmiştir. Çalışma alanı ve yakın çevresini içeren jeoloji haritalarından yararlanılarak bölge hakkında ön bilgiler edinilmiş̧ir. Arazi ve büro çalışmalarında kullanılmak üzere inceleme alanının 1/2000 ölçekli topoğrafik sayısal haritası Hatay Büyükşehir Belediyesi'nden temin edilmiştir.

\subsubsection{Arazi Çalışmaları}

Saha çalışmaları kapsamında inceleme alanındaki zeminlerin ve kayaların mühendislik özelliklerinin belirlenmesi amaciyla Jeolojik ve Jeoteknik Etüt Raporu kapsamında 45-50 m arasında değişen 8 adet sondaj kuyusu, bu çalışma kapsamında ise 12 $\mathrm{m}$ derinliğinde 1 adet presiyometre kuyusu açılmıştır. Presiyometre çalışmalarında 4 farklı seviyede ölçümler yapılmıştır. Ayrıca 8 adet sondaj kuyusundan 6 tanesi inklinometre çalışmalarında kullanılmışıtır.

\subsubsection{Sondajlar}

İnceleme alanında yer alan zemin ve kaya birimlerinin bileşimlerini, kalınlıklarını, litolojik, fiziksel ve mekanik özelliklerini belirlemek ve yeraltı suyu durumuyla ilgili bilgi edinmek amacıyla şev tepesinde sondaj kuyuları açılmıştır (Şekil 6). Sondaj kuyularının lokasyon planı Şekil 7'de sunulmuştur. Şev yamacının kayma tehlikesi yüksek olduğundan ve kayan kütleye ulaşımın sarp arazi koşulları yüzünden elverişli olmaması sebebiyle kayan kütle sondajlarda kesilememiştir. 


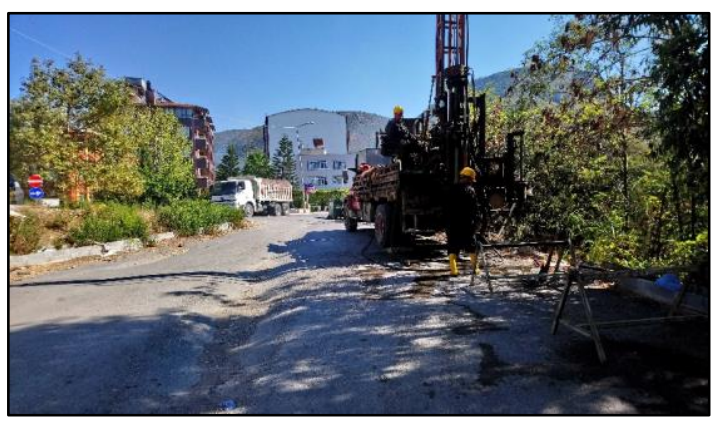

Şekil 6. Arazide yapılan sondaj çalışmaları

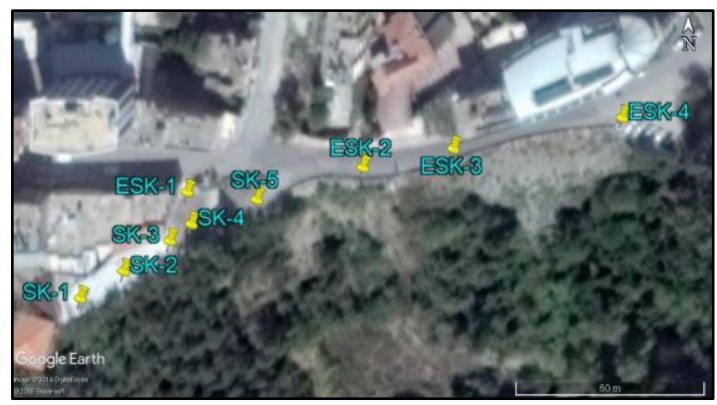

Şekil 7. Sondaj kuyularının lokasyon planı

\subsubsection{Laboratuvar Çalışmaları}

Sondaj çalışmalarından elde edilen zemin ve kaya numuneleri Akademi Jeolojik Jeoteknik Etüd Proje Müh. İnş. San. Tic. Ltd. Şti.'ye ait laboratuvara gönderilmiştir. Laboratuvar çalışmalarıyla zemin ve kaya birimlerin fiziksel ve mekanik özelliklerinin belirlenmesi amaçlanmıştır. Sondaj çalışmaları ile elde edilen zemin ve kaya numunelerinden litolojik birimleri en uygun şekilde ayıklanmış ve bunların üzerinde uygun deneyler yapılmıştır. Bu kapsamda 58 adet karot 13 adet SPT ve 2 adet örselenmemiş numune laboratuvar deneylerine tabi tutulmuştur.

\subsubsection{Büro Çalışmaları}

Büro çalışmaları kapsamında şev analizinde kullanılacak parametrelerin laboratuvar sonuçları, arazi gözlemleri ve RocData (versiyon 2017) bilgisayar yazılımı kullanılarak belirlenmiş olup üç boyutlu şev stabilite analizlerinde kullanılmıştır. Analiz çalışmaları Slide 2D (versiyon 2018) ve Slide 3D (versiyon 2017) bilgisayar yazılımları ile yapılmıştır. Geri analiz yöntemi ile şev ile ilgili parametreler elde edilmiştir. Ayrıca arazi çalışmalarından elde edilen veriler değerlendirilmiş olup arazide alınan inklinometre ölçümleri ile şevlerin hareket durumu incelenmiştir.

\section{ARAŞTIRMA BULGULARI}

\section{1. Ínceleme Alanı Jeolojisi}

Şev analizi yapılacak bölgenin yeraltı jeolojisi incelendiğinde şev hesaplamalarına dahil olan birimlerin kil ağırlıklı olduğu (siltli kil, kiltaşı gibi birimler) görülmektedir. Ayrıca şevde 6-7 metre aralığındaki derinliklerde yeraltı suyu bulunması, kiltaşı birimi ve altındaki tüm birimlerin suya doygun olduğunu göstermektedir. Sondaj çalışmalarından yola çıkılarak, çalışma alanı ve çevresinin yeraltı jeolojisini temsil eden jeolojik kesitler hazırlanmıştır. Sondaj kuyuları arası kesit Şekil 8'de şev kesiti Şekil 9'da sunulmuştur. İnceleme alanında 0,3 ile 4,5 metre arasında değişen kalınlıklarda dolgu malzemesi bulunmaktadır. İnceleme alanında gözlemlenen siltli kil biriminin kalınlığı 1,2-6,0 metre arasında değişmektedir. Kiltaşı birimi ise tüm kuyularda siltli kil biriminden sonra gözlemlenmiş ve kuyu sonlarına kadar devamlılık göstermiştir.

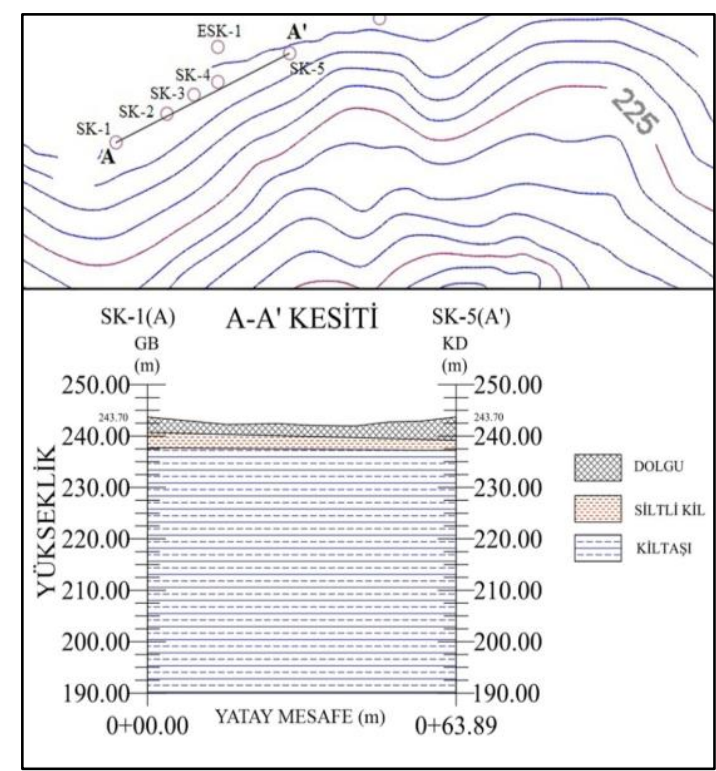

Şekil 8. Kuyular arası jeolojik kesit 


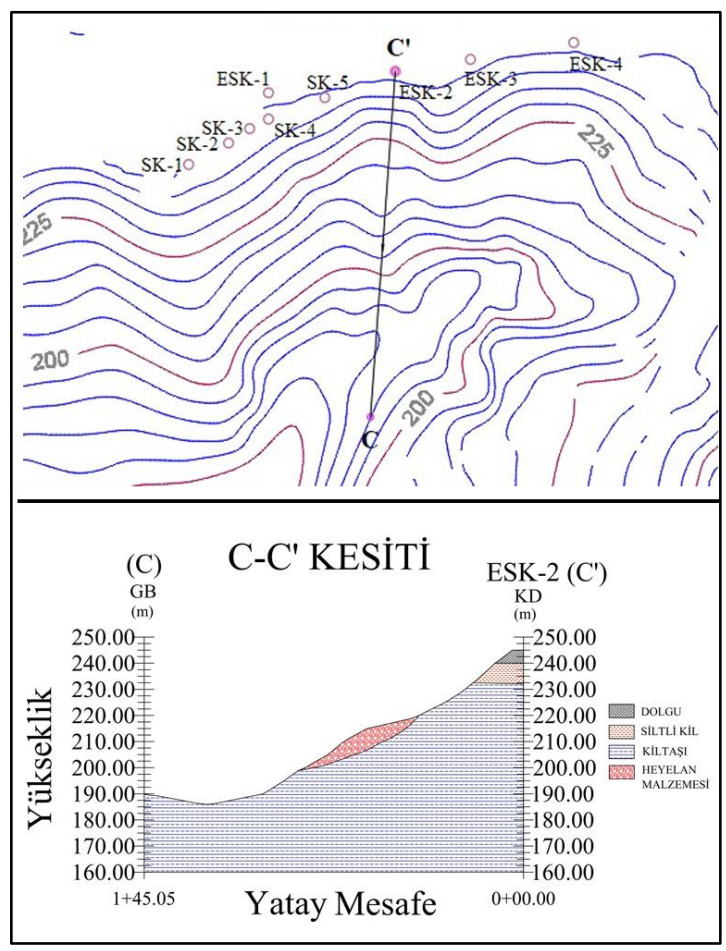

Şekil 9. Kayma yönü boyunca alınan jeolojik kesit

\section{2. İnklinometre Ölçümleri}

Arazide yapılmış olan inklinometre çalışmaları sonucunda ESK-4 kuyusunda ilk 4 metrelik derinlikte 0,6 mm'ye kadar bir deplasman ölçülmüştür. En yüksek ölçüm SK-2 kuyusunda yapılmış olup $45 \mathrm{~m}$ derinlikte deplasman miktarı $10 \mathrm{~mm}$ olarak ölçülmüştür. İnklinometre ölçümleri değerlendirildiğinde bölgede hareketin halen devam ettiği anlaşılmaktadır. Ancak derinlerde meydana gelen bu hareket sadece bir kuyuda ölçüldüğü için derinlerde mevcut olabilecek bir kayma yüzeyinin varlığı hakkında destekleyici bilgilere ulaşlamamıştır.

\section{3. Şev Analizinde Kullanılacak Parametrelerin Seçimi}

Kısa dönem duraylılık analizlerinde kullanılacak parametreler drenajsız dayanım parametreleri olup uzun dönem duraylılık analizlerinde kullanılacak parametreler ise efektif dayanım parametreleridir. $\mathrm{Bu}$ çalışmaya konu olan inceleme alanında analiz edilecek şevin tepesine ani bir yükleme yapılmayacağından zemin içerisinde bulunan su zamanla drene olmaktadır. Bu sebeple uzun dönem duraylılık analizleri yapılması ve suya doygun birimlere ait sev analizinde kullanılacak parametrelerin efektif parametreler olmas1 gerekmektedir.

Eğer bir şevde kayma gerçekleşmiş ise o şev ile ilgili rezidüel dayanım parametreleri kullanılır. Rezidüel dayanım parametreleri hem direk kesme deneyi hem de geriye dönük şev analiziyle tespit edilebilmektedir [4]. Ayrıca RocData yazılımı ile parametreler elde edilmiş ve bu parametrelerle de analizler yapılmıştır.

RocData ile kiltaşına ait kohezyon ve içsel sürtünme açısı elde edebilmek için güncel numunelerden 20 adet tek eksenli basınç dayanımı değerinin ortalaması alınarak RocData için $\mathrm{q}_{\mathrm{un}}$ değeri elde edilmiş ve 58 adet doğal birim hacim ağırlık değerinin ortalaması alınmıștır. Böylece girdi parametreleri qun $=3,3 \mathrm{MPa}$ ve $\gamma \mathrm{n}=$ $17,9 \mathrm{kN} / \mathrm{m}^{3}$ olarak hesaplanmıştır. Hoek Brown sınıflandırması için jeolojik dayanım indeksi değeri kullanılmış ve litolojik birim RocData yazılımından kiltaşı olarak seçilmiştir (Çizelge 1).

Geri analiz hesaplamalarında tüm litolojik birimler için Mohr-Coulomb yenilme zarfı tanımlanmıştır. Kiltaşının rezidüel dayanım parametrelerine ulaşabilmek için hedef birim olarak kiltaşı birimi seçilmiş diğer birimlerin değerleri sabit bırakılmıştır. Geri analizde hesaplanacak kohezyon değer aralığ $0-80 \mathrm{kPa}$ ve içsel sürtünme açıs1 değer aralığ $10-60^{\circ}$ olarak seçilmiş ve parametre hesab1 için probabilistik (olasılıksal) yöntem kullanılmıştır. Kayma türü dairesel olmayan (noncircular) olarak seçilmiş ve kayma yüzeyi adedi $=1$ olarak seçilmiştir. Elde edilen dağılım grafiğinde, geri analiz için tanımlanan kohezyon ve içsel sürtünme açısı değer aralığında 5000 adet parametre çifti hesaplanmış ve bunların arasından güvenlik katsayısı yaklaşı olarak 1'e eşit olan 96 adet parametre çifti belirlenmiştir (Şekil 10). Geri analizle elde edilen kohezyon-içsel sürtünme açısı grafiğinden regresyon çizgisine yakın olan bir değer çifti seçilmiştir (Çizelge 2). 
İnceleme alanındaki dolgu malzemenin kohezyon (c), içsel sürtünme açısı $(\phi)$ ve elastisite modülü [5] değerlerinin tayini için presiyometre deneyi sonuçlarından faydalanılmıştır [6]. Örselenmemiş numuneler üzerinde, Tepehan Formasyonuna ait siltli kil biriminin makaslama dayanım parametrelerinin belirlenmesi amacıyla üç eksenli basınç deneyi ve zemindeki normal gerilmelerin hesaplanabilmesi amaciyla doğal birim hacim ağırlık $\left(\gamma_{\mathrm{n}}\right)$ deneyi yapılmıştır. Kiltaşına ait dayanım parametreleri ise direk kesme deneyi, geri analiz ve RocData ile olmak üzere 3 farklı yöntemle elde edilmiştir. Şevlere yakın yapıların yapı yükü tanımlanmış ve AFAD, Afet ve Acil Durum Yönetimi Başkanlığı, Deprem Dairesi Başkanlığı tarafından hazırlanan Türkiye Deprem Tehlike Haritasından elde edilen pik yüzey ivmesi (PGA) 0,4 olup, maksimum yer ivmesinin yarıs1 sismik yük katsayısı olarak alınmıştır (Çizelge 2).

Çizelge 1. RocData girdi parametreleri

\begin{tabular}{|c|c|c|}
\hline \multicolumn{2}{|l|}{ Ortalama tek eksenli basınç dayanımı ( $\left.\mathrm{q}_{\mathrm{un}}\right)$} & $3,3 \mathrm{MPa}$ \\
\hline \multicolumn{2}{|l|}{ Ortalama doğal birim hacim ağırlık $\left(\gamma_{\mathrm{n}}\right)$} & $17,9 \mathrm{kN} / \mathrm{m}^{3}$ \\
\hline \multicolumn{2}{|l|}{ Jeolojik dayanım indeksi (GSI) } & 54 \\
\hline \multirow{2}{*}{$\begin{array}{l}\text { Kiltaşına ait RocData yazılımı tarafından tanımlı } \\
\text { bazı değerler }\end{array}$} & $\mathrm{mi}$ & 4 \\
\hline & MR & 250 \\
\hline \multicolumn{2}{|l|}{ Şev yüksekliği } & $50 \mathrm{~m}$ \\
\hline \multicolumn{2}{|l|}{ Yenilme kriteri } & Mohr-Coulomb \\
\hline
\end{tabular}

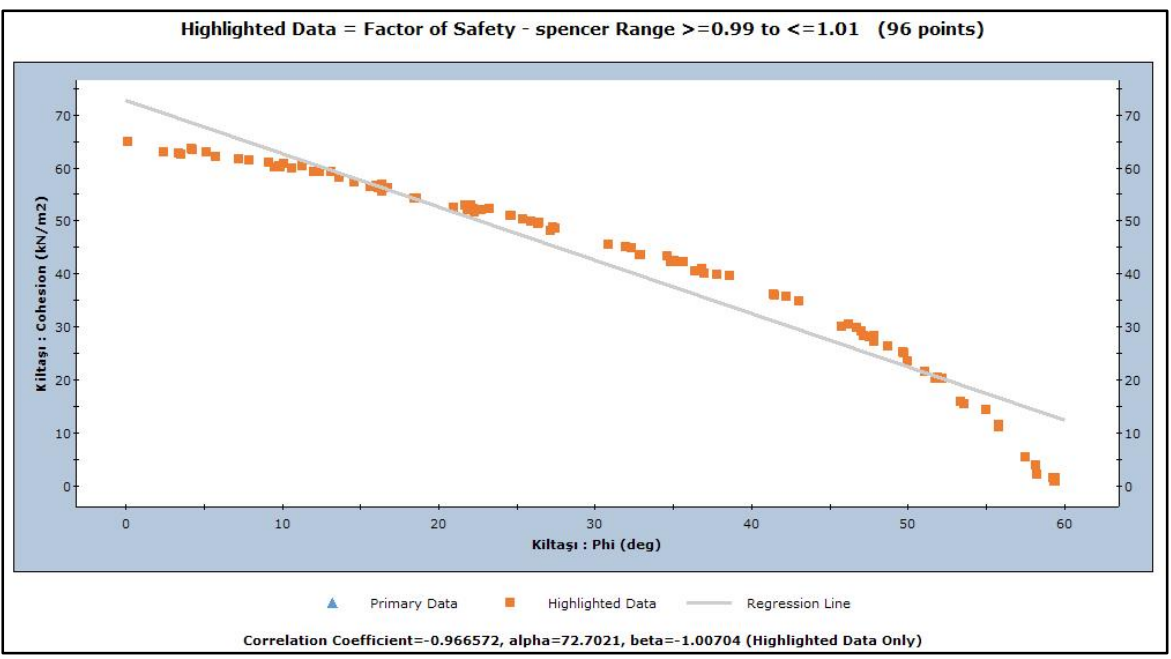

Şekil 10. Geri analiz sonucunda elde edilen parametre çiftlerine ait grafik

Çizelge 2. Şev analizinde kullanılacak parametreler

\begin{tabular}{|l|c|c|c|c|c|}
\hline & Dolgu & Siltli kil & Kiltaşı direk kesme & $\begin{array}{c}\text { Kiltaşı } \\
\text { rocdata }\end{array}$ & $\begin{array}{c}\text { Kiltaşı } \\
\text { geri analiz }\end{array}$ \\
\hline $\mathbf{c}(\mathbf{k P a})$ & 118,9 & 62,9 & 20,47 & 115 & 43 \\
\hline$\phi\left(^{\circ}\right)$ & 58 & 7,5 & 21,6 & 26 & 35 \\
\hline$\gamma_{\mathbf{n}}\left(\mathbf{k N} / \mathbf{m}^{\mathbf{3}}\right)$ & 18 & 17,8 & 17,9 & 17,9 & 17,9 \\
\hline Ru & 0 & 0 & 0,54 & 0,54 & 0,54 \\
\hline Sismik yük katsayısı & \multicolumn{5}{|c|}{0,2 (kayma yönünde, yatay) } \\
\hline Yapı yükü $\left(\mathbf{k N} / \mathbf{m}^{\mathbf{2}}\right)$ & \multicolumn{5}{|c|}{20} \\
\hline
\end{tabular}




\section{4. Şevin Kayma Mekanizması ve Uygun Analiz Yöntemi Seçimi}

$\mathrm{Bu}$ çalış̧mada Slide şev analiz yazılımlarında en doğru sonuçları veren yöntemlerden biri olan Spencer yöntemi $[7,8]$ kullanılmıştır. İnceleme alanında, kayan kütle ve civarında yapılan gözlemler sonucunda gerçekleşen kaymaların hem zemin hem kaya türü birimlerde gerçekleştiği tespit edilmiştir. Kayma düzleminin zeminlerde dairesel şekilde, kaya biriminde ise dairesel olmayan bir şekilde devam ettiği gözlemlenmiştir. Şevdeki hareket kompleks kayma şeklinde olduğu için ve pratik olması açısından hızlı bir şekilde çözümlemeler yapılabilmesi için Spencer yönteminin uygun olacağı düşünülmüştür.

\subsection{1. Üç Boyutlu Şev Stabilite Analizi}

Slide 3D, limit denge yöntemi kullanarak üç boyutlu şev stabilite analizi yapan bir yazılımdır. Çalışmada "Slide 3D" olarak adlandırılan yazılım kullanılmıştır. Slide 2D'de analizlerde kullanılan düzlemsel kesitlerde sadece iki boyutlu modelleme ile analiz yapılabilirken Slide 3D ile üç boyutlu olarak kompleks bir şev geometrisi kolaylıkla analiz edilebilmektedir. Ayrıca Slide 3D yazılımının güçlü geometri modelleme ve veri yorumlama özelliği sayesinde kullanıcı dostu olup hılı bir şekilde analizler yapılabilmektedir. Slide 2D yazılımında kayma yüzeyinin stabilite analizlerinde kullanılabilen Bishop, Janbu, Spencer, Sarma, Morgenstern-Price (GLE) [8, 9] vb. gibi yaygın limit denge metotları da Slide 3D yazılımında kullanılabilmektedir. Kayan kütle çevresi arasındaki makaslama direnci iki boyutlu analizlerde ihmal edilmesine rağmen üç boyutlu analizlerde makaslama direnci hesaba katılmaktadır. Slide 3D yazılımı aynı Slide 2D gibi limit denge analiz yöntemlerini kullandığı için kayan kütleler dilimler halinde çözümlenir. Slide 3D arazi modeli üzerinde litolojik birimlerin oluşturulması için yazılıma sondaj kuyularının yerleri ve birimlerin kalınlıkları girilerek korelasyon yapılmas1 yeterlidir. Slide 3D yazılımında analiz yapılan bölgenin dört ayrı pencerede farklı açılardan görünümü ekranda aynı anda görüntülenir (Şekil 11). Böylece farklı açılardan kayan kütle ve şev çevresi rahatlıkla incelenebilmektedir. Ayrıca modellenen şevler her açıdan kolaylıkla görüntülenebildiğinden destek sistemleri ve yap1 yükleri rahatlıkla uygulanabilmektedir.

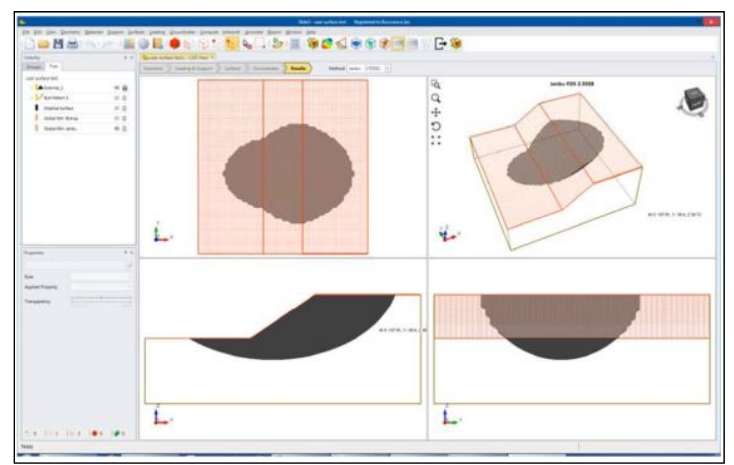

Şekil 11. Slide 3D yazılımından örnek bir ekran görüntüsü

Şev stabilite analizlerinde şevin durumu güvenlik katsayısı (GK)'nın 1'den büyük, 1'den küçük veya 1'e eşit olmasına göre değerlendirilmiştir. Güvenlik katsayısı 1'den büyük olduğu durumlarda şev duraylı olarak değerlendirilmiştir.

Şev analizinde kullanılan parametreler farklı yöntemlerle elde edilmiştir. Bu parametreler direk kesme deneyi, geri analiz ve RocData yazılımı ile üç farklı şekillerde elde edilmiștir. Parametrelerin elde edilme şekillerine göre farklı senaryolar üzerinde durulmuştur. Her bir senaryoda kiltaşına ait makaslama dayanım parametreleri farklı değerler almaktadır. Şev duraylılı̆̆ının tespitinde önce her bir senaryo için statik durum ele alınarak analiz yapılmış daha sonra her bir senaryonun deprem durumunda göstereceği davranış hesaba katılarak analiz yapılmıştır. Kiltaşının suya doygun olduğu kabul edilerek 3 adet statik durum analizi ve 3 adet deprem durumu analizi olmak üzere toplam 6 adet analiz yapılmıştır. Oluşturulan üç boyutlu arazi modelinde çalışma alanı civarında veri toplanan ve problemli olan bölge sınırlandırılmış olup analizler bu bölgeye yoğunlaştırılmıştır. Elde edilen güvenlik katsayıları Çizelge 3 'te verilmiştir.

Elde edilen sonuçlara göre şev stabilitesi ile ilgi ortaya konan üç farklı senaryo değerlendirildiğinde 
direk kesme deney sonuçlarının kullanıldığ 1 . senaryoda elde edilen sonuçların araziyi yansıtmayacak kadar düşük olduğu görülmektedir. Direk kesme deneyinde yalnızca bir numuneye dayanarak analiz yapıldığından elde edilen sonuçların güvenirliliği düşüktür. 2. senaryoda ampirik yöntemleri kullanan RocData yazılımı ile elde edilen parametreler ise tüm diğer senaryolardan daha yüksek güvenlik katsayılarının hesaplanmasına sebep olmuştur. 3. senaryoda geri analiz ile elde edilen parametreler ile hesaplamalar yapılmış ve 1 . senaryo ile 2 . senaryo değerlerinin arasında değerler elde edilmiştir. Geri analiz yönteminin kullanıldığı senaryoda elde edilen sonuçlar diğer senaryolarla elde edilen değerlerin arasında değerler olduğundan ayrıca geri analizle elde edilen parametrelerin daha önce kayma hareketi gerçekleşen bir şev için kullanılmasının daha doğru olacağından 3. senaryo iyileştirmeler ve öneriler için baz alınmıștır. Arazide gerçekleşecek kaymaların 3. senaryodaki gibi olacağı kabul edilmiştir.

Çizelge 3. Üç boyutlu şev analizi sonuçları

\begin{tabular}{|l|c|c|}
\hline & $\begin{array}{c}\text { Statik durum için güvenlik } \\
\text { katsayıları }\end{array}$ & $\begin{array}{c}\text { Deprem durumu için güvenlik } \\
\text { katsayıları }\end{array}$ \\
\hline Direk kesme deneyi & 0,45 & 0,37 \\
\hline RocData yazılımı & 1,28 & 1,00 \\
\hline Geri analiz & 0,88 & 0,67 \\
\hline
\end{tabular}

3. senaryoda; Slide3D yazılımına girilen parametreler Çizelge 2'de verilmiştir. İlk önce statik durum analizi yapılmış daha sonra da sismik yük katsayısı eklenerek deprem koşullu analiz yapılmıştır. Statik durumda en düşük $\mathrm{GK}=0,88$ olarak hesaplanmış deprem durumunda ise en düşük $\mathrm{GK}=0,672$ olarak hesaplanmıştır. Her iki durumda da elde edilen güvenlik katsayılarının 1'den küçük olması nedeniyle üçüncü senaryoda yamacın duraylı olmadığı sonucuna ulaşılmıştır. Statik durumda beklenen kaymanın şeve yakın olan yapının önünden itibaren gerçekleşeceği görülmektedir (Şekil 12). Deprem durumunda ise beklenen kaymanın şeve yakın olan yapının hemen hemen yarısını içine aldığı ve şev tepesinde bulunan mevcut fore kazıklar sayesinde genişliğinin sınırlandığı görülmektedir (Şekil 13).

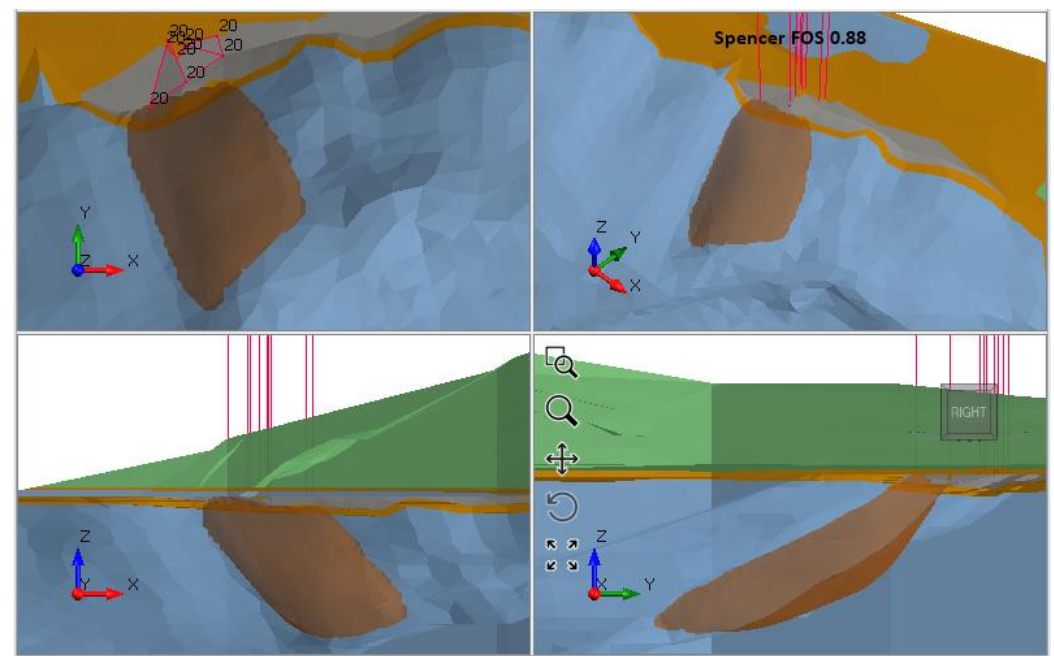

Şekil 12. Geri analizden elde edilen girdi parametreleri kullanılıp statik durumdaki kayma hareketi sonuçlarını gösteren Slide3D ile oluşturulmuş üç boyutlu model (senaryo 3). Her bir model farklı perspektiflerden potansiyel kayma alanını (koyu kahverengi kütle) göstermektedir 


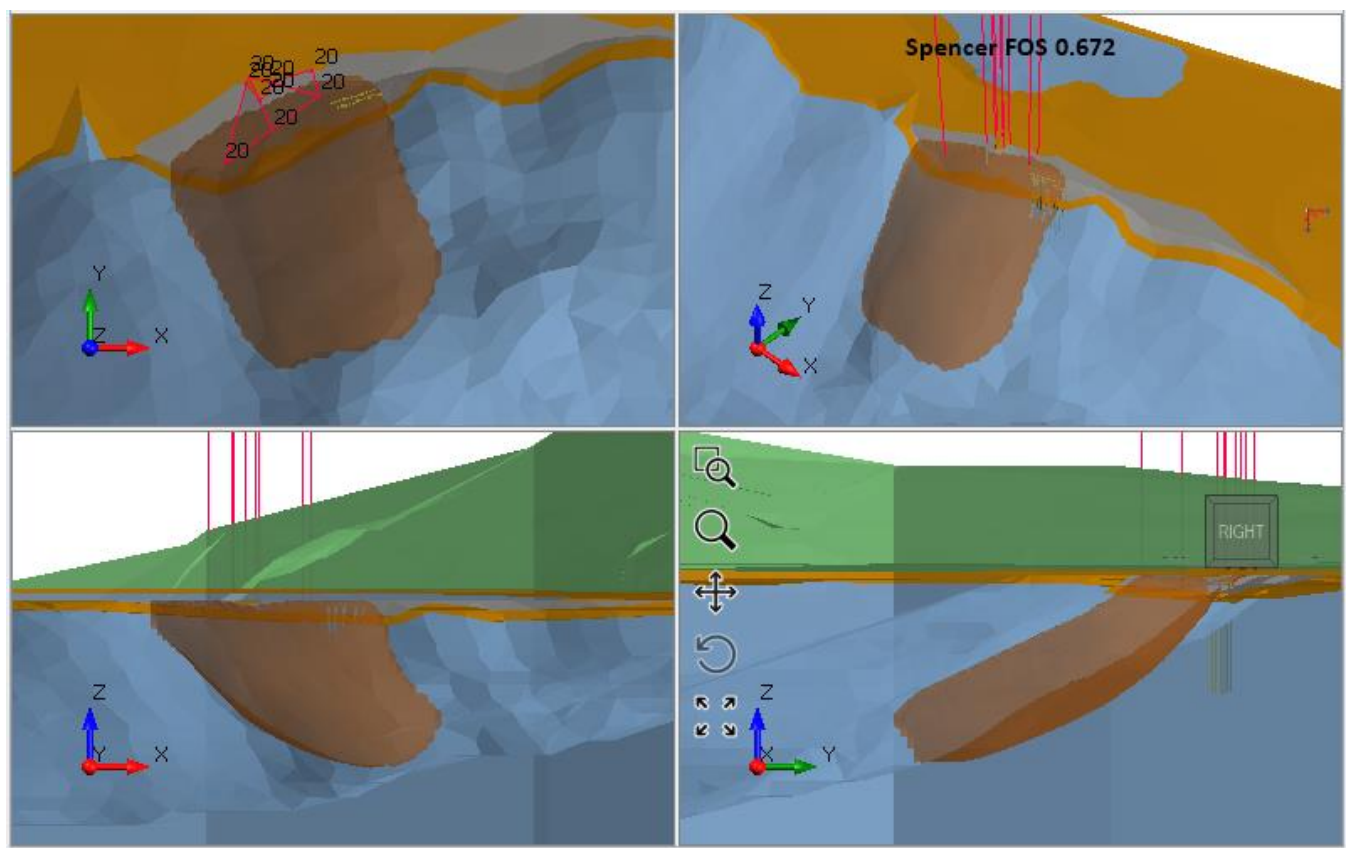

Şekil 13. Geri analizden elde edilen girdi parametreleri kullanılıp deprem durumundaki kayma hareketi sonuçlarını gösteren Slide3D ile oluşturulmuş üç boyutlu model (senaryo 3). Her bir model farklı perspektiflerden potansiyel kayma alanını (koyu kahverengi kütle) göstermektedir

\subsection{Sev İyileștirme Yöntemleri}

Çalışma kapsamında iyileştirme yöntemi olarak fore kazıklar önerilmiştir. Slide3D yazılımı kullanılarak üç boyutlu analizlerle farklı boyutlarda ve farklı sayıda fore kazık uygulamaları analiz edilmiş ve en uygun ve ekonomik tasarım değerlendirilmiştir. Elde edilen analiz sonucunda önerilen tasarımda fore kazıklar 25 ile 35 metre aralığında değişen uzunluklara sahip toplamda 175 adettir. Uygulanacak fore kazıklar 3 sira halinde denenmiş ve şevin farklı noktalarında konumlandırılmıştır (Şekil 14). Bu senaryoda ilk sura şev tepesinde 35 metre uzunluğunda 30 adet betonarme fore kazık varsayılmıştır. İkinci sıra yaklaşık şev ortasında olup 30 metre uzunluğunda 60 adet betonarme fore kazıktan oluşmaktadır. Üçüncü sıra şev topuğuna yakın olup 25 metre uzunluğunda 85 adet betonarme fore kazıktan oluşmaktadır. Tüm fore kazıkların çapı $140 \mathrm{~cm}$ ve merkezden merkeze kazık aralıkları $160 \mathrm{~cm}$ ve kesme dayanımları $2500 \mathrm{kN}$ olarak alınmıştır. İyileştirme çalışmaları kapsamında onlarca senaryo denenmiş olup en ideal sonuçların 3 sıra fore kazık çalışmasıyla elde edildiği görülmüştür. Ayrıca şevin tepesinde eski kazıklar gibi iki sıra fore kazık uygulanmaya çalışmış ancak yapı yüklerinden dolayı eklenen bu yeni iki sıra fore kazık verimli olmamıştır (Şekil 15, 16).

Denenen bu tasarımda statik durumda en düşük GK değeri 0,880 'den 1,366'ya yükselmiştir. Deprem durumunda ise en düşük GK 0,672'den 1,064'e yükselmiştir (Çizelge 4). Böylece iyileştirme sonucunda statik durumda önceden duraylı olmayan şev duraylı hale getirilmiştir. Limit denge prensibine göre deprem durumundaki güvenlik katsayısı 1'den büyük olduğu için şevin duraylı olduğu tanımlanmıştır. Ancak deprem koşulunda elde edilen bu güvenlik katsayısı bire yakın olduğu için deprem durumunda şevin durumu kritiktir. Çalışma kapsamında yapılan iyileștirme çalıșması mutlak bir çözüm değildir alternatif iyileştirmelerle ve şev üzerindeki yapı yüklerinin azaltılmasıyla bu güvenlik katsayıs1 arttır1labilir. 


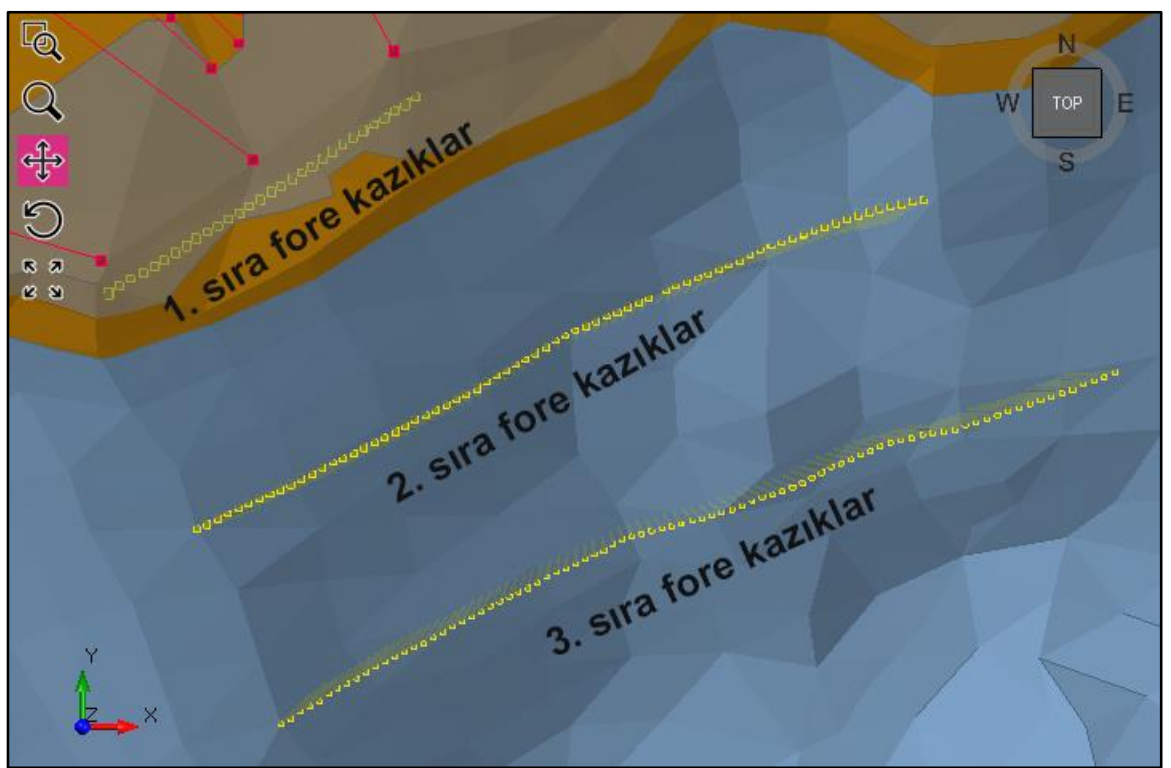

Şekil 14. Şevin üç farklı bölgesine (tepe, orta ve topuğa yakın bölgelere) uygulanacak şekilde önerilen fore kazıkların (sarı renkli hatlar) arazideki konumları

Çizelge 4. İyileştirme sonucu elde edilen güvenlik katsayıları

\begin{tabular}{|l|c|c|}
\hline \multirow{2}{*}{ Önerilen iyileştirme } & \multicolumn{2}{|c|}{ Güvenlik sayısı } \\
\cline { 2 - 3 } & Statik durum & Deprem durumu \\
\hline Pasif kazık ile iyileştirme & 1,37 & 1,06 \\
\hline
\end{tabular}

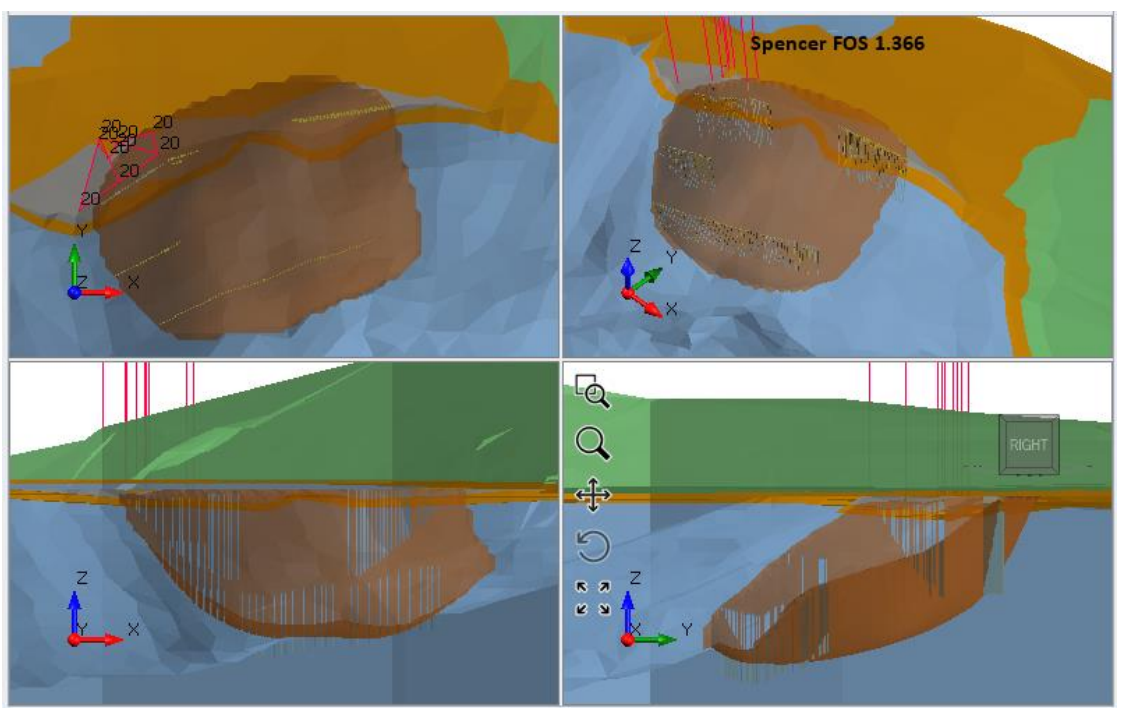

Şekil 15. Geri analizden elde edilen girdi parametreleri kullanılarak oluşturulmuş statik durumdaki kayma hareketini gösteren modelin fore kazık iyileştirmesi sonrasındaki durumunu gösteren Slide3D ile oluşturulmuş üç boyutlu şev modeli (senaryo 3) 


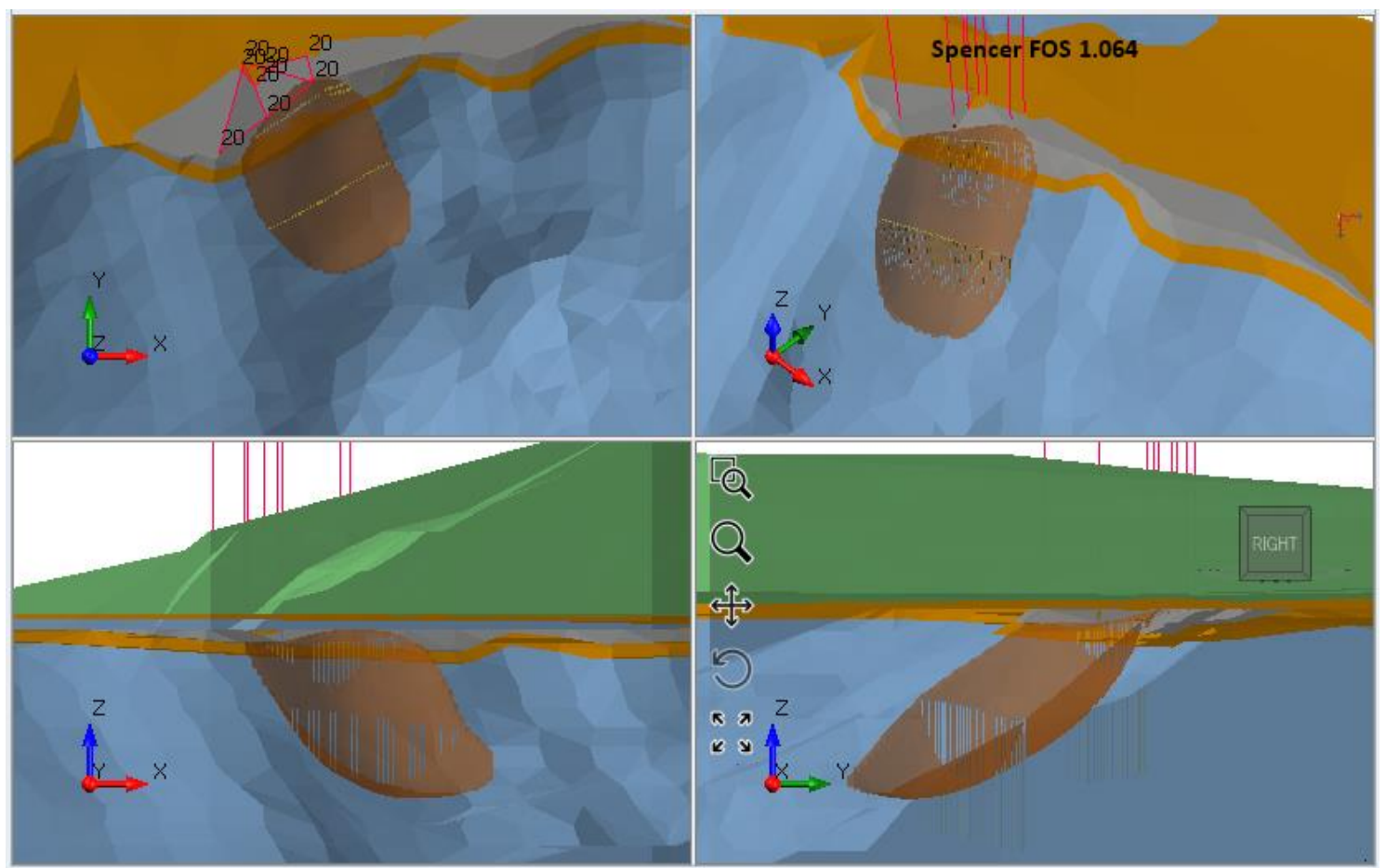

Şekil 16. Geri analizden elde edilen girdi parametreleri kullanılarak oluşturulmuş deprem durumundaki kayma hareketini gösteren modelin fore kazık iyileştirmesi sonrasındaki durumunu gösteren Slide3D ile oluşturulmuş üç boyutlu şev modeli (senaryo 3)

\section{TARTIŞMA VE SONUÇLAR}

Bu çalışmada Hatay ili Defne ilçesi Harbiye mahallesinde yer alan Şelaleler bölgesindeki şevlerin durumu mühendislik jeolojisi açısından incelenmiş, şevlerin stabilite problemleri araştırılmış, bilgisayar yazılımları (Slide 2018 ve Slide3 2017) ile çözümlemeler yapılmış ve elde edilen veriler yardımıyla önerilerde bulunulmuştur.

Saha çalışmaları kapsamında inceleme alanındaki zeminlerin ve kayaların mühendislik özelliklerinin belirlenmesi amacıyla Jeolojik ve Jeoteknik Etüt Raporu kapsamında [3], 45-50 m arasında değişen 8 adet sondaj kuyusu, bu çalışma kapsamında ise $12 \mathrm{~m}$ derinliğinde 1 adet presiyometre kuyusu açılmıştır. Presiyometre çalışmalarında 4 farklı seviyede ölçümler yapılmıştır. Ayrıca 8 adet sondaj kuyusundan 6 tanesi inklinometre çalışmalarında kullanılmıştır.
İnceleme alanında yapılan sondajlarda $0,30-4,5 \mathrm{~m}$ kalınlığında dolgu malzeme, 1,2-6,0m kalınlığında siltli kil ve bu birimleri takiben kuyu sonlarına kadar devamlılık gösteren kiltaşı birimi gözlemlenmiştir. Sondajlarda gözlemlenen litolojik birimler Tepehan Formasyonu içerisinde yer almaktadır. Ayrıca inceleme alanı ve civarında yapılan jeolojik çalışmalarda Kaleboğazı Formasyonuna ait kireçtaşı birimi ile Okçular Formasyonuna ait kireçtaşı birimine ve Kuvaterner yaşı ı Traverten birimine rastlanılmıştır.

Arazide yapılmış olan inklinometre çalışmaları sonucunda ESK-4 kuyusunda ilk 4 metrelik derinlikte 0,6 mm'ye kadar bir deplasman ölçülmüştür. En yüksek ölçüm SK-2 kuyusunda yapılmış olup $45 \mathrm{~m}$ derinlikte deplasman miktarı $10 \mathrm{~mm}$ olarak ölçülmüştür. İnklinometre ölçümleri değerlendirildiğinde bölgede hareketin halen devam ettiği anlaşılmaktadır. Ancak derinlerde 
meydana gelen bu hareket sadece bir kuyuda ölçüldüğü için derinlerde mevcut olabilecek bir kayma yüzeyinin varlığı hakkında destekleyici bilgilere ulaşılamamıştır.

Arazi ve laboratuvar deneylerinden elde edilen şev parametreleri Dolgu malzeme için $\mathrm{C}=118,9 \mathrm{kPa}$, $\phi=58^{\circ}$; siltli kil için $\mathrm{C}=62,9 \mathrm{kPa}, \phi=7,5^{\circ}$ şeklindedir. Geri analizlerden elde edilen ve şev analizinde kullanılacak kiltaşı parametreleri ise Cgerianaliz $=43 \mathrm{kPa}, \phi$ gerianaliz $=35^{\circ}$ şeklindedir. Kiltaşı birimin tamamen suya doygun olduğu kabul edilmiş ve boşluk suyu basıncı dolgu için $R u=0$, siltli kil için $R u=0$ ve Kiltaş 1 çin $R u=0,54$ olarak hesaplanmıştır. Birimlere ait ortalama doğal birim hacim ağırlık değerleri kullanılmış olup bu değerler dolgu için $\gamma \mathrm{n}=18 \mathrm{kN} / \mathrm{m}^{3}$, siltli kil için $\gamma \mathrm{n}=17,8 \mathrm{kN} / \mathrm{m} 3$ ve kiltaşı için $\gamma \mathrm{n}=17,9 \mathrm{kN} / \mathrm{m}^{3}$ şeklindedir.

Stabilite analizleri, şev parametrelerinin elde edilme yöntemlerine göre 3 farklı senaryoda hem statik koşullarda hem de depremli koşullarda yapılmıştır. 1. senaryoda arazi ve laboratuvar deneylerinden elde edilen parametreler, 2. senaryoda RocData ile elde edilen parametreler ve 3. senaryoda ise geri analizlerden elde edilen parametreler kullanılmıştır. Tüm analizlerde Spencer Yöntemi kullanılarak dairesel olmayan kayma yüzeyleri üzerinden GK (güvenlik katsayısı) hesaplamaları yapılmıştır. 1. Senaryoda statik durumda en düşük $\mathrm{GK}=0,453$ olarak hesaplanmış deprem durumunda ise en düşük $\mathrm{GK}=0,339$ olarak hesaplanmış olup $\mathrm{GK}<1$ olduğu için duraysızlık söz konusudur. 2. senaryoda statik durumda en düşük $\mathrm{GK}=1,284$ olarak hesaplanmış deprem durumunda ise en düşük $\mathrm{GK}=1,005$ olarak hesaplanmış olup statik durumda $\mathrm{GK}<1$ olduğu için duraysızlık deprem durumunda $\mathrm{GK}=1$ olduğu için limit denge söz konusudur. 3. senaryoda statik durumda en düşük $\mathrm{GK}=0,880$ olarak hesaplanmış deprem durumunda ise en düşük $\mathrm{GK}=0,672$ olarak hesaplanmış olup $\mathrm{GK}<1$ olduğu için duraysızlık söz konusudur. RocData yazılımı ampirik eşitlikler ile hesaplamalar yapmakta olup verdiği değerler yüksek çıkmıştır. Bir adet direk kesme deneyi kullanılarak yapılan analizde deney sayısının az olması sebebiyle sonuçların güvenilirliği düşüktür. Geri analiz yönteminin kullanıldığı senaryoda elde edilen sonuçlar diğer senaryolarla elde edilen değerlerin arasında değerler olduğundan ayrıca geri analizle elde edilen parametrelerin daha önce kayma hareketi gerçekleşen bir şev için kullanılması daha doğru olacağından 3. senaryo, iyileştirmeler ve öneriler için baz alınmıştır. Arazide gerçekleşecek kaymaların 3. senaryodaki gibi olacağı kabul edilmiştir.

Şev iyileştirme yöntemlerinden pasif kazık yöntemi kullanılmıştır. Fore kazıklar 3 sıra halinde önerilmiş ve şevin farklı noktalarında konumlandırılmıştır. İlk sıra şev tepesinde olup 35 metre uzunluğunda 30 adet betonarme fore kazıktan oluşmaktadır. İkinci sıra yaklaşık şev ortasında olup 30 metre uzunluğunda 60 adet betonarme fore kazıktan oluşmaktadır. Üçüncü sıra şev topuğuna yakın olup 25 metre uzunluğunda 85 adet betonarme fore kazıktan oluşmaktadır. Fore kazıklar $140 \mathrm{~cm}$ çapta ve merkezden merkeze 160 cm aralıklı olup gibi kazıkların kesme dayanımları $2500 \mathrm{kN}$ olarak alınmıştır. İyileştirme sonras1 statik durumda en düşük GK değeri 0,880'den 1,366'ya yükselmiş deprem durumunda ise en düşük GK 0,672 'den 1,064'e yükselmiştir. İyileştirme sonrası GK $>1$ değerleri elde edildiğinden duraysız olan şevde stabilite sağlanmıştır. Limit denge prensibine göre deprem durumundaki güvenlik katsayısı 1'den büyük olduğu için şevin duraylı olduğu tanımlanmıştır. Ancak deprem koşulunda elde edilen bu güvenlik katsayısı bire yakın olduğu için deprem durumunda şevin durumu kritiktir. Makale kapsamında yapılan iyileştirme çalışması mutlak bir çözüm olmayıp alternatif iyileştirmelerle ve şev üzerindeki yapı yüklerinin azaltılmasıyla bu güvenlik katsayısı arttırılabilir. İnceleme alanındaki problemli şevlerin jeolojisi incelendiğinde killi birimlerin hakim olduğu görülmektedir. $\mathrm{Bu}$ killi birimlerin bünyesindeki suyun drene olma süresi uzun olduğundan boşluk suyu basıncı stabilite için problemler yaratmaktadır. İnceleme alanının şelaleler bölgesinde olması sebebiyle devaml su varlığından kaynaklı problemlerin mevcut olacağından şevler üzerinden drenaj ağlarının oluşturulması önerilmektedir. 


\section{KATKI BELİRTME}

\author{
$\mathrm{Bu}$ çalışma Çukurova Üniversitesi Bilimsel \\ Araştırma Projeleri Koordinasyon birimi \\ Tarafından desteklenmiştir (FLY-2018-10502 nolu \\ Proje kapsaminda).
}

\section{KAYNAKLAR}

1. Duyan, M., 2019. Harbiye (Hatay) Şelaleler Bölgesindeki Şev Duraysılıklarının Mühendislik Jeolojisi Açısından Değerlendirilmesi. Ç.Ü. Fen Bilimleri Enstitüsü, Yüksek Lisans Tezi, Adana, 203.

2. Selçuk, H., 1985. Kızıldağ-Keldağ-Hatay Dolayının Jeolojisi ve Jeodinamik Evrimi. MTA Rapor No: 7787, Ankara

3. Tüfenkçi, O., 2015. Hatay Büyükşsehir Belediyesi Hatay İli Defne İlçesi Harbiye Mahallesi Ürgen Caddesinde Meydana Gelen Heyelanın Zemin İncelemesi Hizmet Alım İşi Jeolojik Jeoteknik Etüt Raporu. Akademi Jeolojik Jeoteknik Etüd Proje Müh. Müş. İnş. San. Tic. Ltd. Şti., Ankara, 75.

4. Duncan, J.M., Wright, S.G., 2005. Soil Strength and Slope Stability. John Wiley \& Sons Inc.

5. Briaud, J.L., Lytton, R.L., Hung, J.T., 1983. Obtaining Moduli From Cyclic Pressuremeter Tests. Journal of Geotechnical Engineering, 109, 657-665.

6. Baquelin, F., Jezequel, J.F., Shields, D.H., 1978. The Pressuremeter and Foundation Engineering. Trans Tech Publications, Clausthal-zellerfeld, Germany, 617.

7. Spencer, E., 1967. A Method of Analysis of the Stability of Embankments Assuming Parallel Inter-slice Forces. Geotechnique, 17(1), 11-26.

8. Spencer, E., 1973. Thrust Line Criterion in Embankment Stability Analysis. Geotechnique, 23(1), 85-100.

9. Bishop, W., 1955. The Use of the Slip Circle in the Stability Analysis of Slopes. Géotechnique, 5(1) 7-17

10. Morgenstern, N.R., 1992. The Evaluation of Slope Stability-a 25 Year Perspective. In Stability and Performance of Slopes and Embankments, Geotechnical Special Pub. 31,
ASCE, New York, 1, 1-26 